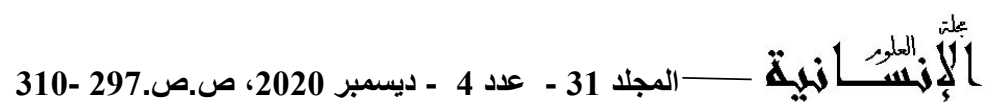

\title{
تجريم التسول بإستغلال الأطفال في القانون الجزائري
}

Criminalization of begging exploitation of children in the Algerian Law.

تاريخ الاستلام : 2020/03/18 ؛ تاريخ القبول : 2020/12/09

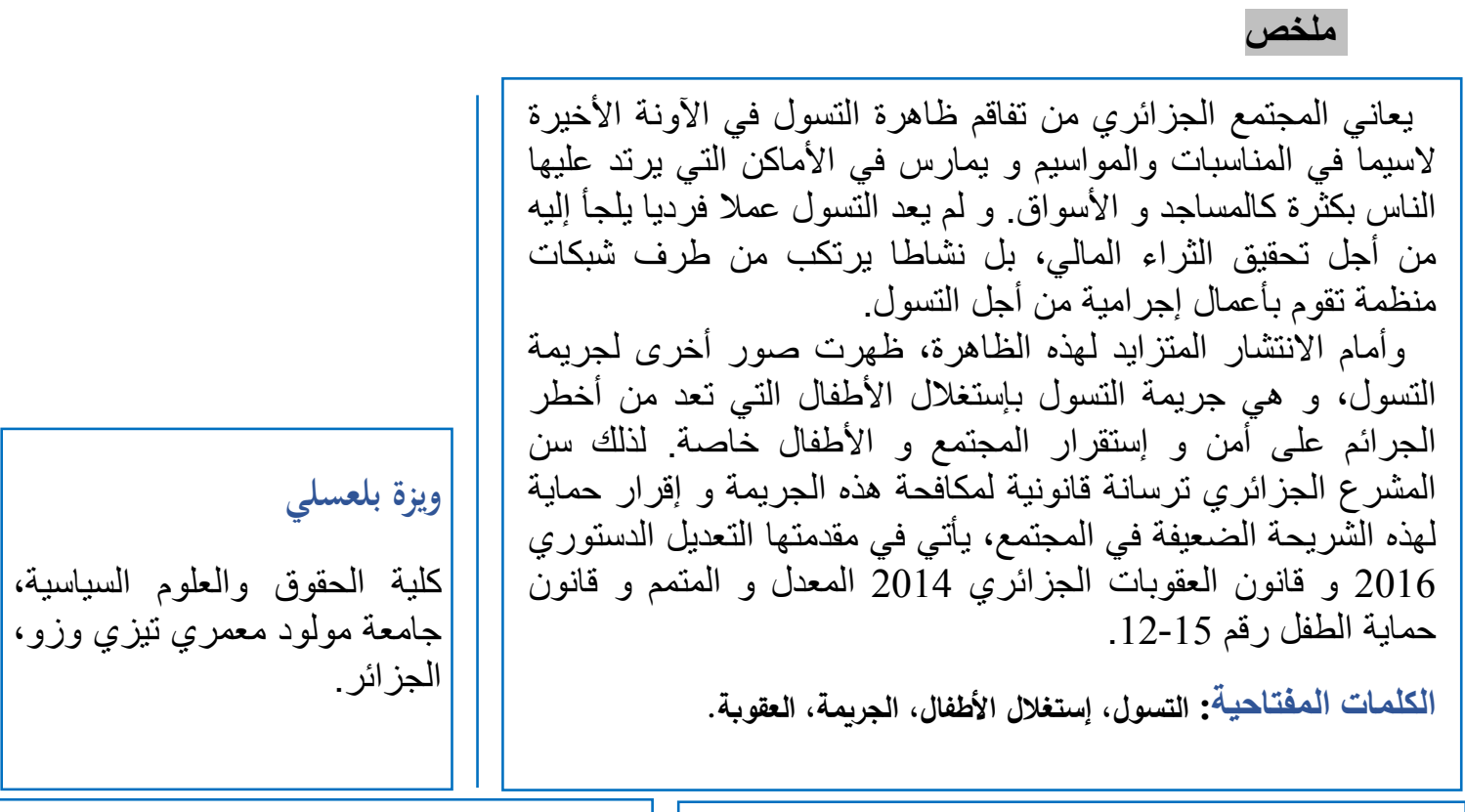

\section{Abstract}

Algerian society is suffering from the growing phenomenon of begging in recent times, especially in the occasions and seasons, and is practiced in places where people are frequent as mosques and marketplaces. Begging is no longer an individual act one resorts to for the purpose of monetary wealth accumulation, but an activity committed by organized networks that carry out criminal acts for the purpose of begging.

In view of the increasing prevalence of this phenomenon, other manifestations of the crime of begging have emerged: begging by exploitation of children, one of the most serious crimes against the security and stability of society and children in particular. Therefore, the Algerian legislator enacted a legal arsenal to combat this crime and to protect this vulnerable segment of the society, foremost of which is the constitutional amendment 2016, the amended Algerian Penal Code 2014 and the Child Protection Act No. 15-12.

Keywords: begging, exploitation of children, crime, punishment.

\section{Résumé}

La société algérienne souffre ces derniers temps, de l'exacerbation de ce phénomène et plus particulièrement lors de certaines occasions et saisons, elle est pratiquée dans des endroits très fréquentés tels les mosquées et les marchés. La mendicité n'est plus un acte individuel auquel on a recours pour obtenir de la richesse financière, mais plutôt une activité commise par des réseaux organisés qui se donnent aux actes criminels avec objectif la mendicité.

La propagation croissante de ce phénomène a engendré l'émergence d'autres aspects du crime de mendicité, celui de mendicité par l'exploitation des enfants qui est un crime des plus dangereux contre la sécurité et la stabilité de la société et des enfants en particulier.

C'est pourquoi, le législateur algérien a institué un arsenal juridique pour lutter contre ce crime et d'instituer une protection légale de cette catégorie vulnérable de la société, par, en premier lieu, la modification constitutionnelle de 2016, le Code pénal algérien 2014, modifié et complété et la loi ${ }^{\circ} 15-12$ sur la protection de l'enfance.

La question qui se pose: Comment le législateur algérien a-t-il régi le crime d'exploitation en mendicité de l'enfant mineur, et a-t-il obtenu par sa politique pénale, une protection efficace pour cet enfant?

Mots clés: mendicité, exploitation des enfants, crime, punition. .

*Corresponding author, e-mail: w.belasli@mail.com 
I

تعد ظاهرة التسول بالأطفال من أخطر أشكال عمالة الأطفال لمساسها بحقوقهم

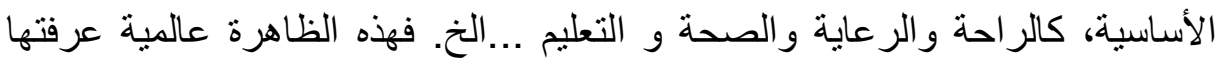
الدول الفقيرة و الغنية على اختلاف أوضاعها الاقتصادية والاجتماعية والسياسية.

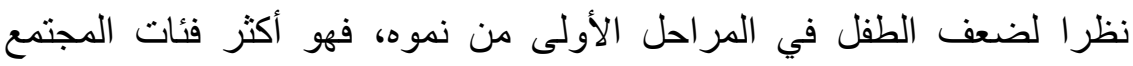

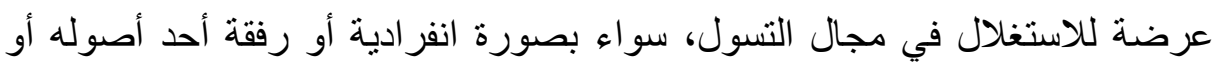
ممن لله السلطة عليه، أو من طرف جماعات منظمة تنشط في الاتجار بالأطفال

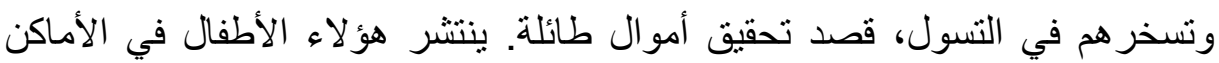
العامة و المساجد و يتو افدون على المحلات من أجل جمع أكبر قدر ممكن من المال

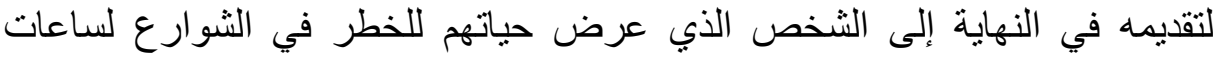
طويلة من اليوم في ظروف مناخية قاسية تؤثر بالدرجة الأولى على صحته الته البدنية.

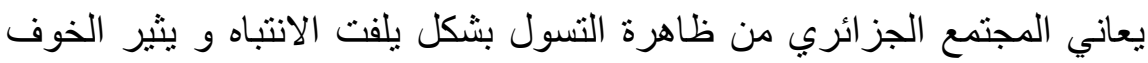

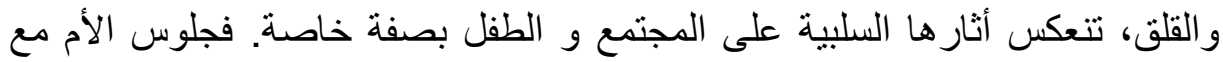
طفلها الرضيع في الثارع أو الأماكن التي يتوافد عليها الناس بكثرة مستعملة الطفل

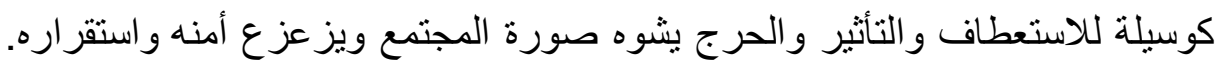

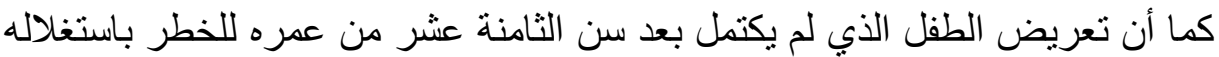

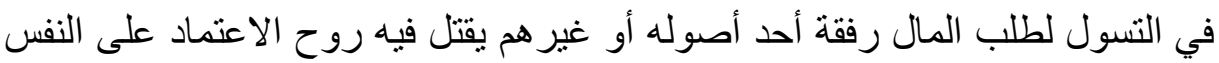
و نمو المسؤولية لديه، كما يحرمه من أبسط حقوقه الطبيعية والمكتسبة، فيدخله في عالم بعيد كل البعد عن عالمه الطفولي يجعله بفقد حسه الطفولي ويتعلم عادات سيئة

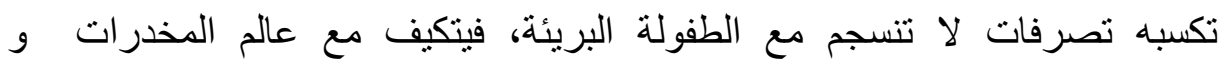
الانحر افات، فيصبح مجرما لا لأ عضو الها صالحا. نظر ا لكل هذه الأخطار والمخاطر، تدخل المشر الأرع الجزائري من أجل حماية الطفل

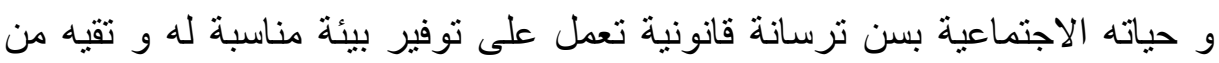

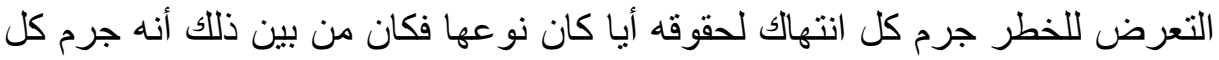

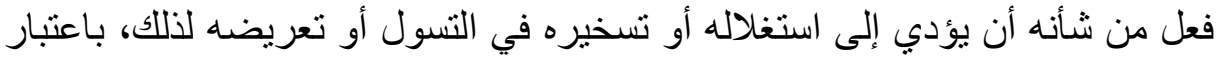

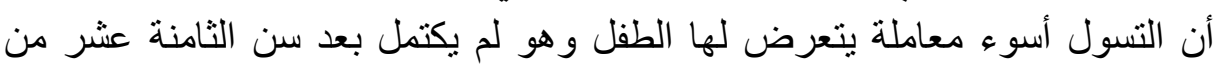
عمره. عززت الدولة حماية الطفل و أرقت به إلى أسمى تشريعاتها، فنصت على هذه

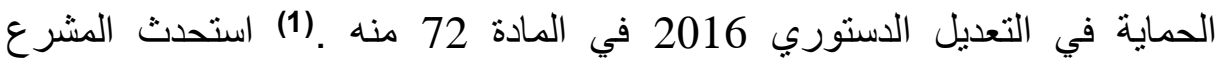
الجزائري آليات فعالة تضمن هذه الحماية من خلال القانون رقم 15-12 المتضمن قانون حماية الطفل (2) كما دعم و أقر هذه الحماية في تعديل قانون العقوبات رقم 1401 (3) كآلية لضمان حمايته من أبشع أنواع الاستغلال في مرحلة تنعدم فيها كمال أهليته. من هنا كانت الإشكالية المطروحة: كيف نظم المشرع الجزائري جريمة استغلال الطفل القاصر في التسول، وهل حقق من ور اء سياسته الجزائية حماية فعالة 


\section{الفقرة الأولى: مفهوم التسول:}

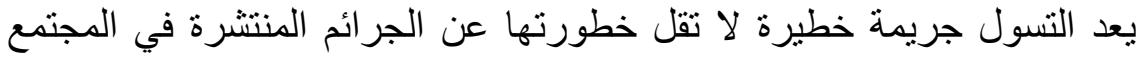

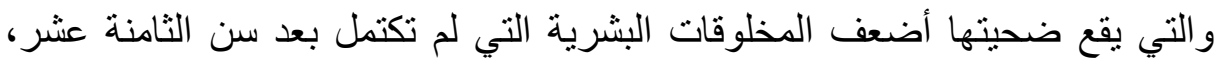

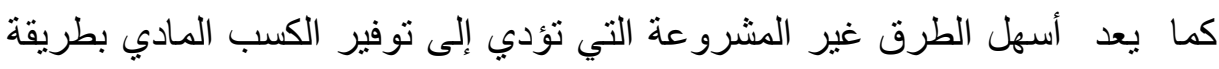

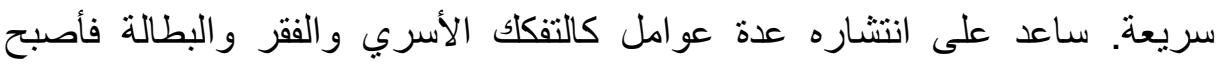
مشكلة اجتماعية يجب تداركها لوضع حد أو التقليل من مساوئها.

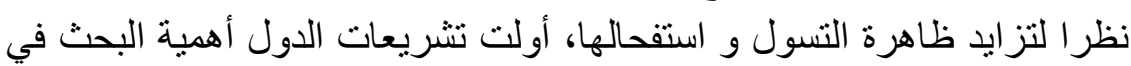

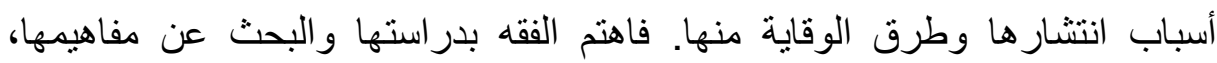

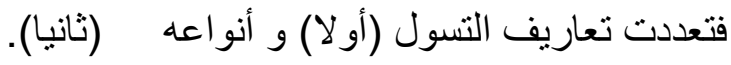
أولا: تعريف التسول:

يعرف التسول على أنه:" طلب الصدقة من الأفراد في الطرق العامة."(4)

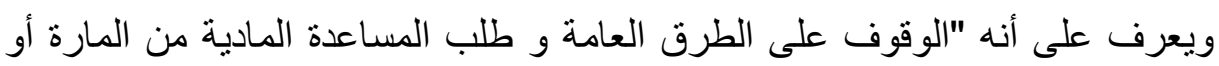

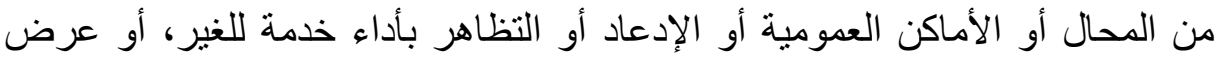

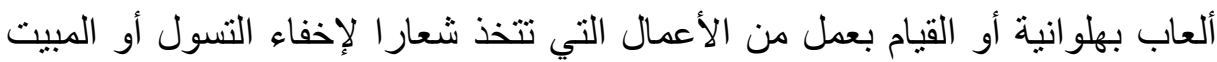

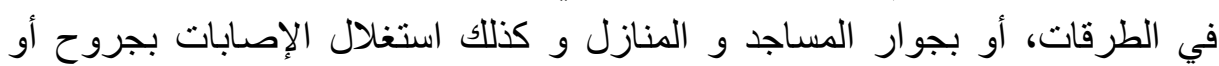

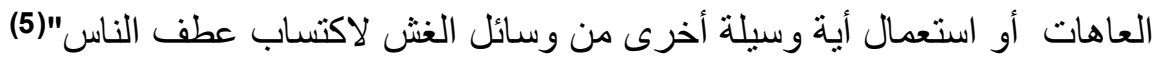

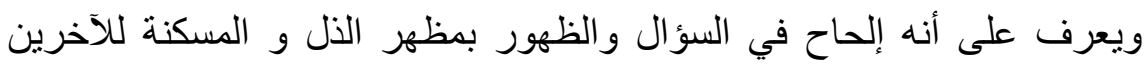
طلبا لعطفه و إستدرار لرحمتهم بقصد الحصول على المال، سواء اقترن هذا السلوك بطلب المال من الآخرين مباشرة أو بعرض سلعة تافهة لبهن عليهم أو بإظهار العاهات البدنية أو حمل صكوك شرعية تحمل ديون أو بارتداء الملابس الرثنة وحمل الأطفال

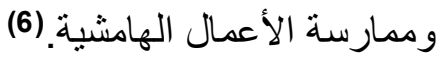

كما عرفه البعض على أنه" سؤال المارة واستجداؤهم بهدف الحصول على الهى مقابل

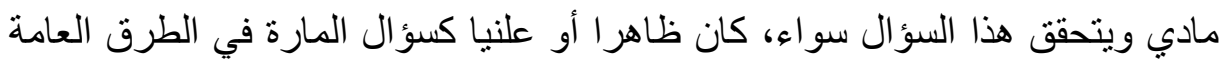

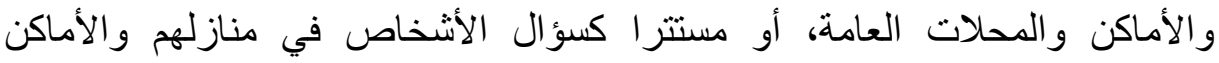

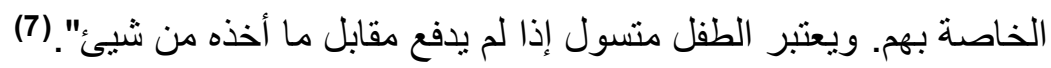

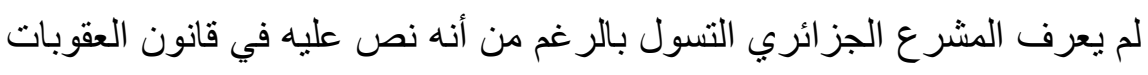
رقم 14-014 وجرمه، حيث اقتصر على تنظيم أركانه وتحديد العقوبة المقررة للأشخاص القائمين به. و طبقا للمادة 195 من القانون أعلاه، اعتبر في حكم المتسول الثخص الذي اعتاد أن يمارس فعل التسول في أي مكان رغم توفر وسائل العيش

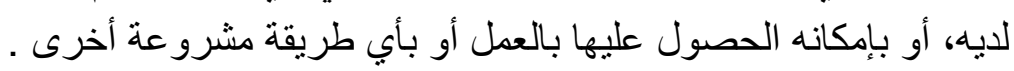

لم يتطرق القانون رقم 15-15 المتعلق بحماية الطفل، لم يتطرق بدوره أيضا إلى

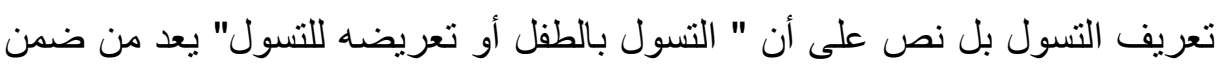

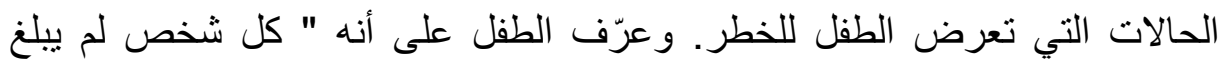

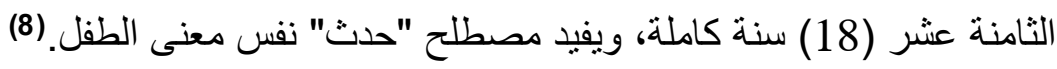
من خلال ما سبق، نستخلص أن التسول يضع الطفل في خطر أو يعرضه لخطر، 
كونه يسيء إلى معاملته ويؤثر على سلامته البدنية والمعنوية فيقف حاجزا أمام بناء

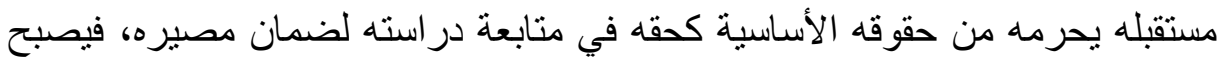
ضحية جريمة ارتكبها أثخاص و دفع ثمنها أطفال أبرياء.

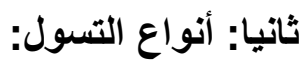

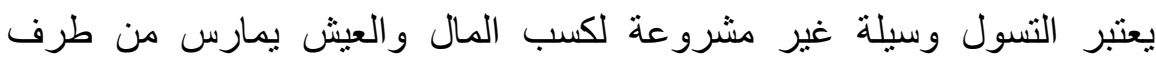

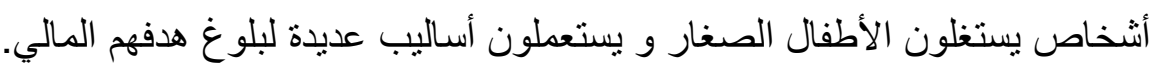
يتخذ التسول عدة أنواع. فهناك التسول الظاهر و الخفي و هناك التسول الموسي التوني

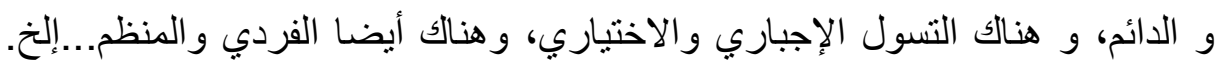

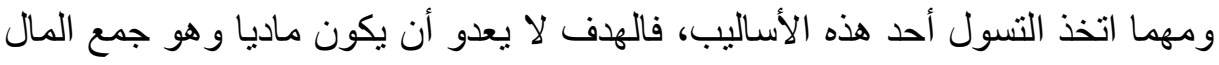
من الصدقات.

ونظر التعدد أساليب التسول نتتاول أهمها التسول المباثر (1) التسول غير المباثر

\section{1 : التسول المباشر:}

يقصد بالتسول المباشر، التسول الظاهر أو العلني أين يمد الثخص المتسول يده

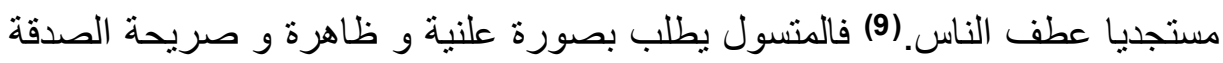

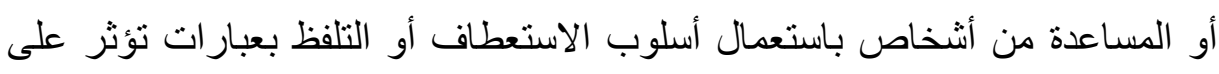

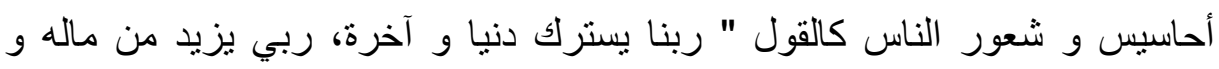
رزقه...إلخ". ولطلب هذه الصدقة ينتقل المنسول بصفة انفرادية أو صحبة أحد أبنائه

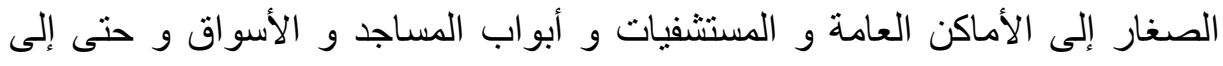

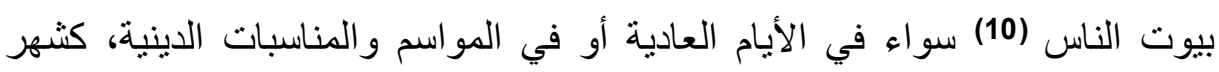
رمضان، العاشوراء، المولد النبوي الثريف...إلخ، وتعتبر هذه المناسبات الثبات أكثر أيام طلب الصدقة و عطف الناس على المحتاج. ولا يكون التسول المباثر محدد الفترة، بل قد يمارس بشكل دائم دائم سواء داخل مدينة واحدة أو من مدينة إلى أخرى. وقد يستقر المتسول يوميا في مكان ثابت ويمد يده مباشرة للناس لطلب الصدقة.

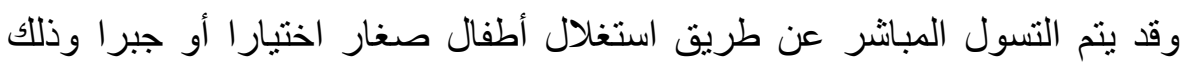

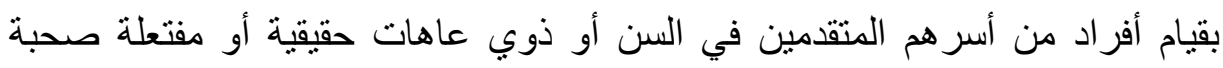

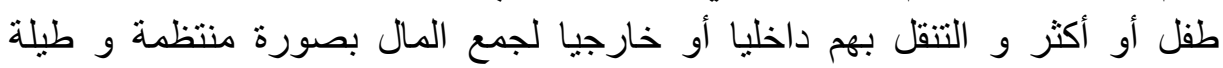
اليوم،(11) بحيث يستغلون إعاقتهم الجسدية أو حالتهم الصحية في التسول لإثارة شفقة الناس.

كما قد يتم التسول المباشر عن طريق اصطحاب أطفال معاقين جسديا أو ذهنيا

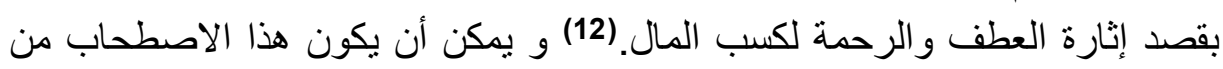

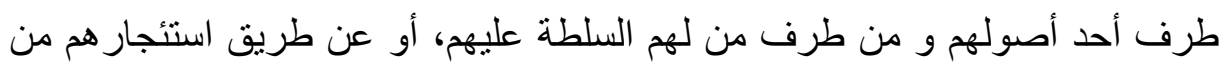

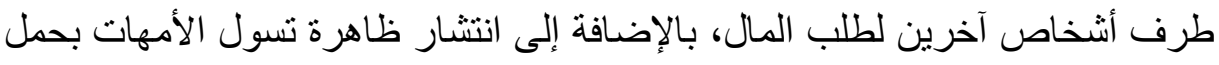

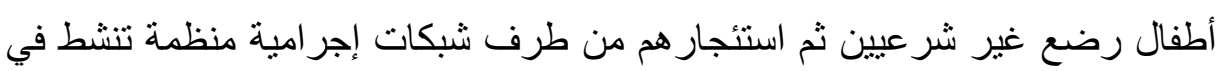


الاتجار بالأطفال والتسول بهم مقابل مبالغ مالية شهرية. حيث تعمل هذه العصابات

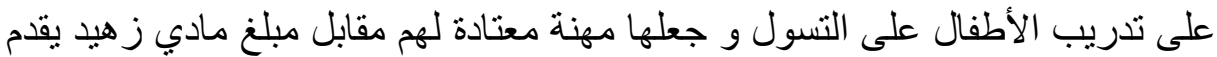
لذويهم (13) أو تسخير الأطفال في التسول مقابل الملجأو الطعام. (14) 2: 2 التسول غير المباشر:

يعرف التسول غير المباشر على أنه التسول المستتر، الخفي أو المقنّع و غير الواضح، يختفي الشخص المتسول في طلب الصدقة وراء عمل بعد من الأعمال المشروعة أو يطلب الصدقة من أشخاص في منازلهم. و و يتخذ هذا التسول عدة صول صور

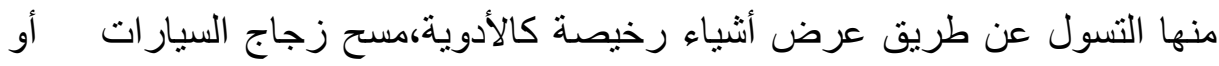

عرض سلع تافهة على الجمهور دون طلبها كالمناديل الورقية و علب الكبريت. كما يتم التسول غير المباشر عن طريق عرض وضلف وصفات طبية ووصفة الدواء مزيفة و كذا فواتير الكهرباء و الماء...إلخ من أجل كسب عطب عطف الناس و و الحصول

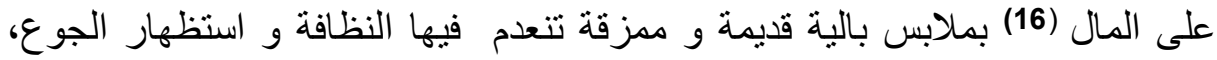
حتى بستعطف الناس و يحصل على المال الحصول عليه.

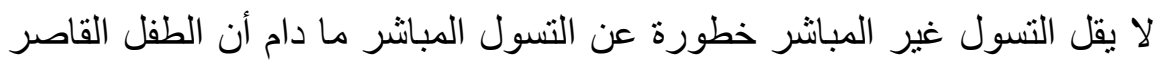

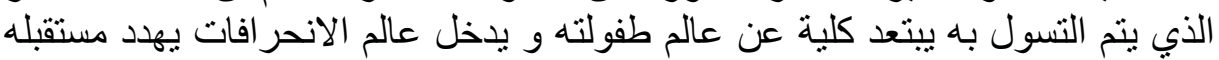

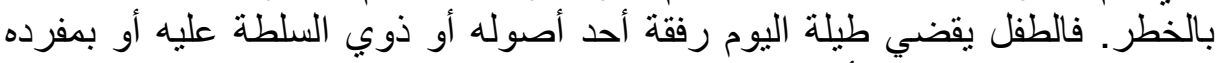

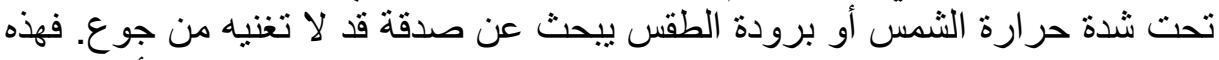

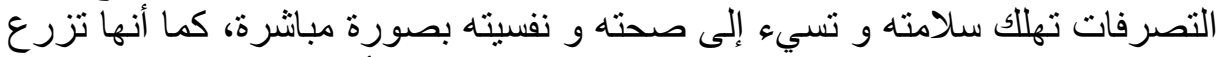

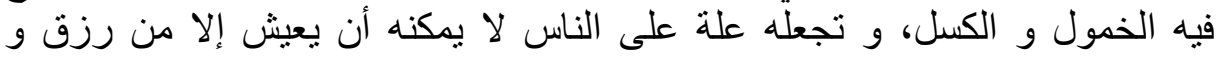

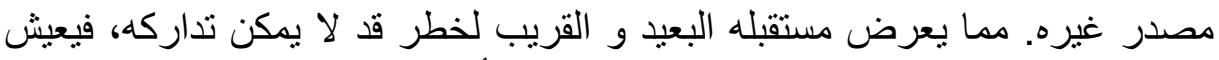

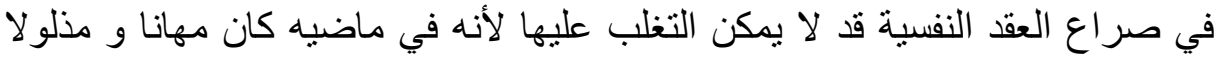
يمد يده لطلب صدر العقة الناس.

\section{الفقرة الثانية: الحماية الجزائية للطفل ضحية الاستغلال في التسول:}

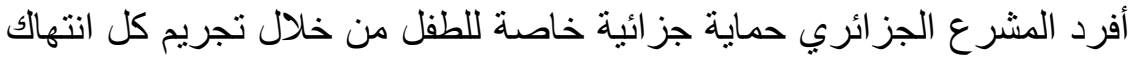

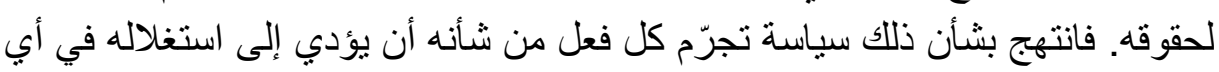

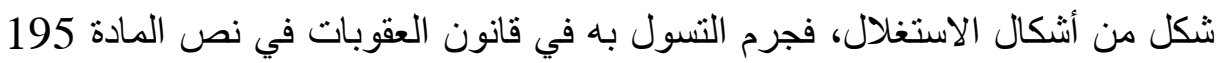
مكرر.

إن التسول بالأطفال القصر يعد جريمة لا يقوم وجودها القانوني إلا بتوافر

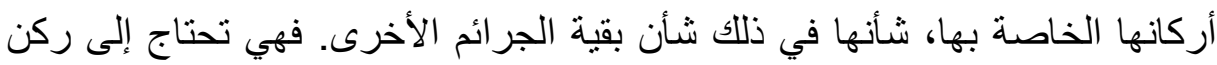

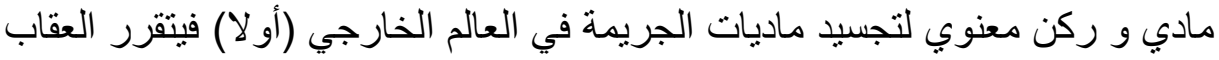
على المسئول عنها دون الطفل القاصر (تانيا) أولا: أركان جريمة التسول بإستغلال الأطفال:

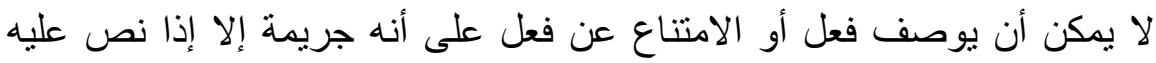

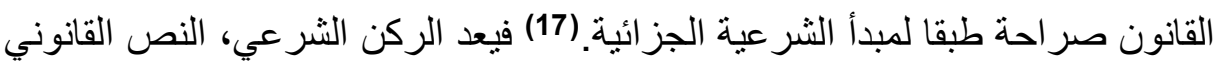

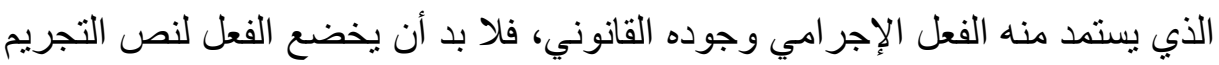

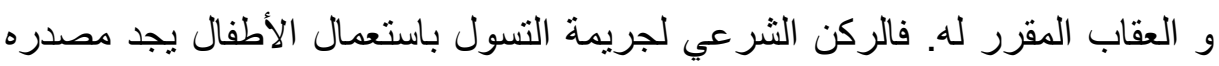

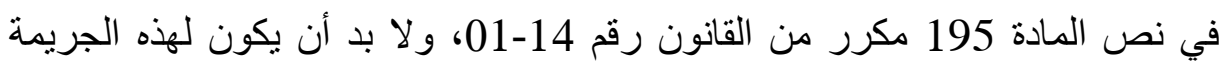




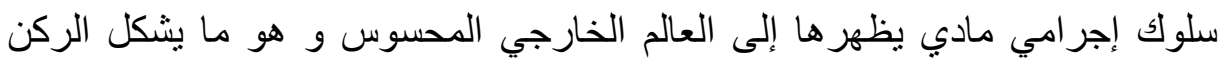

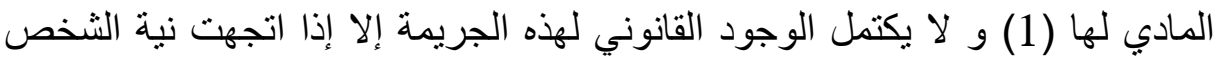

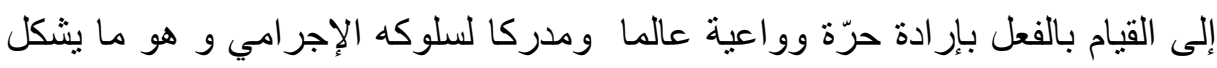

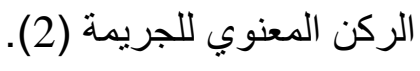

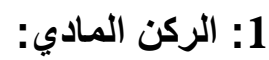

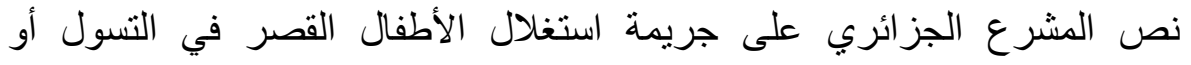
تعريضهم للتسول عن عمر لم يكمل ثمانية عشر(18) سنة، في المادة 195 مكرر من الترن

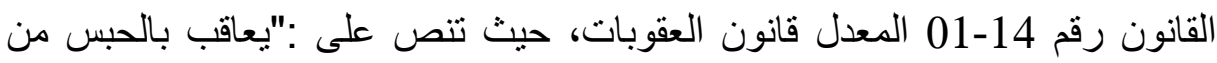

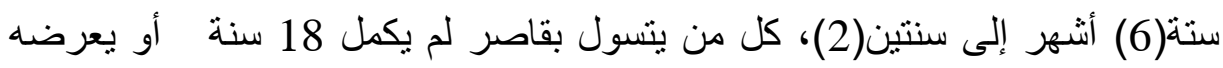
للتسول. تضاعف العقوبة عندما يكون الفاعل أحد أصول القاصر أو أي شخص له له

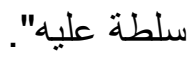
من خلال نص هذه المادة تتضح عناصر الركن المادي لجريمة التسول باستعمال

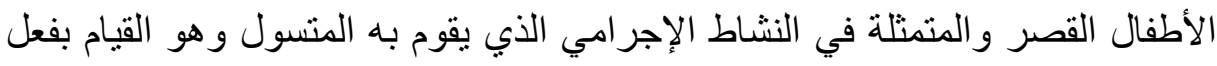

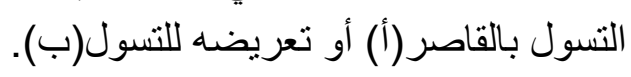
أـأن يكون ضحية جريمة التسول طقلا قاصرا لم يكمل 18 سنة: إذا كانت الضحية

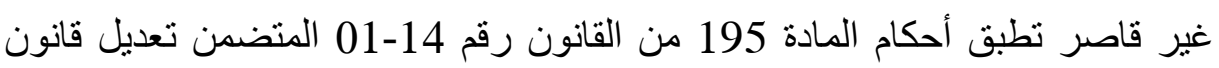

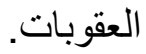

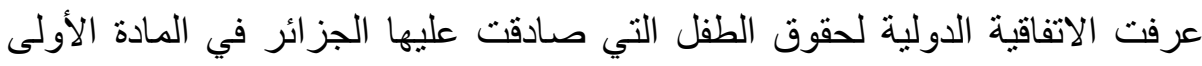

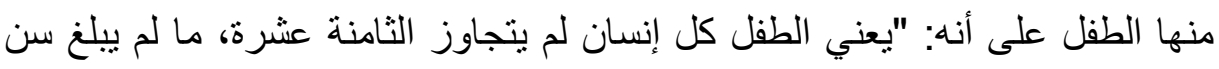

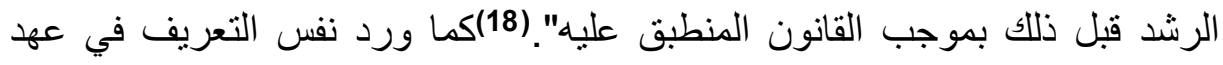

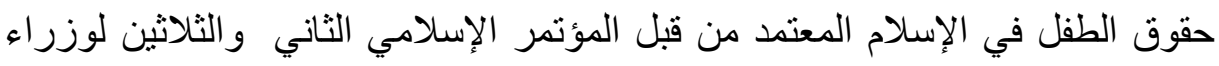

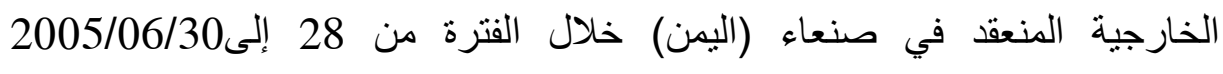

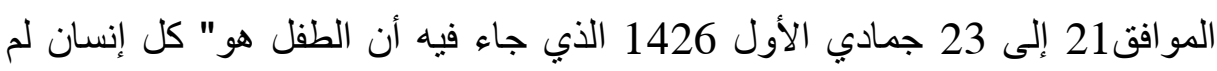
يبلغ سن الرشد وفقا للقانون المطبق عليه".

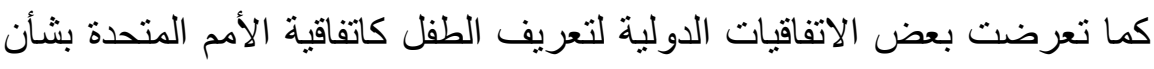

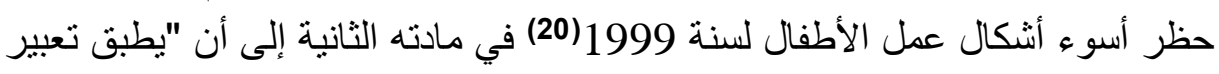

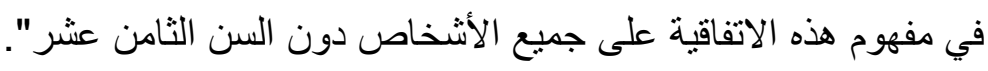

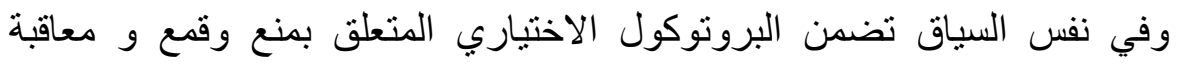

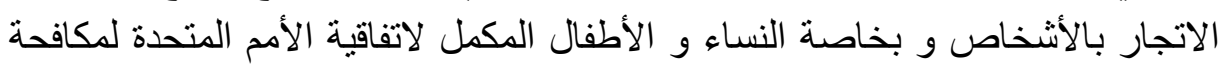

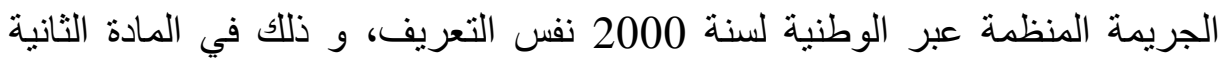

فقرة (د). (21) أما بالنسبة للقانون الجزائري، فلم يتخذ موقفا واحدا بالنسبة لسن الطفل تارة يحدده

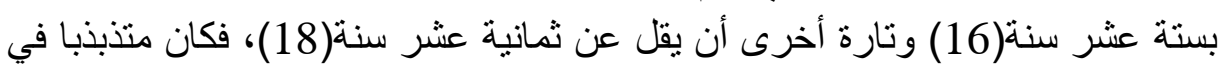
موقفه حتى في الدصطلحات التي يستعطها للتعبير عن الطفل فتارة بطلق عليه الطفل 
الحدث كما فعل في القانون رقم 15-12 المتعلق بحماية الطفل، وتارة أخرى بطلق

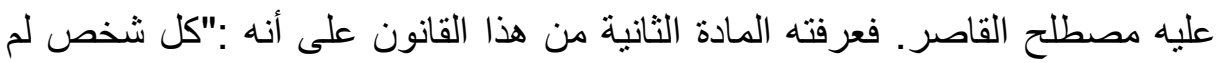
يبلغ الثامنة عشر (18) كاملة، يفيد مصطلح"حدث" نفس المعنى".

ب -قيام الثخص المتسول بتعريض قاصر لم يكمل 18 سنة للتسول: يعتبر التسول بقاصر لم يكمل 18 سنة أو تعريضه للنسول من العناصر الأساسية التي يتشكل منها الركن المادي لجريمة التسول باستعمال قاصر طبقا للمادة 195

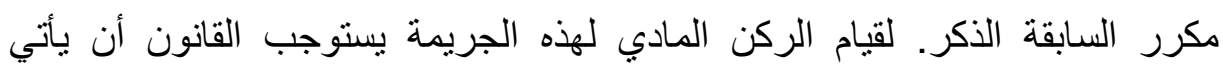

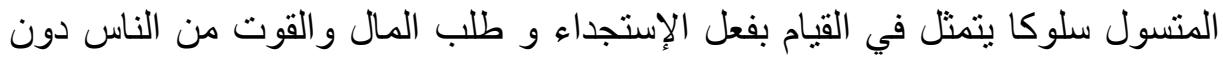
مقابل، وذللك بأخذ قاصر لم يكمل 18 سنة و التسول به في مختلف الأماكن. لقد نصت نفس المادة 195 مكرر أعلاه على معاقبة كل شخص يتسول بقاصر،

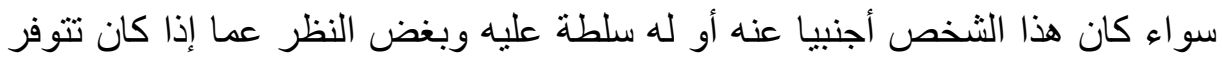

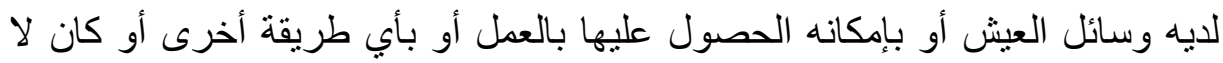

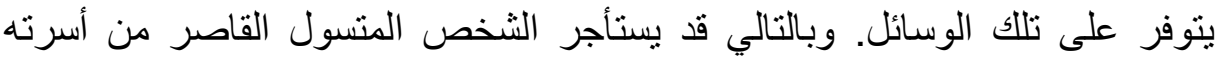
خصيصا لاستغلاله و استعماله كأداة مصاحبة و مساعدة للقيام بمختلف أعمال التسول

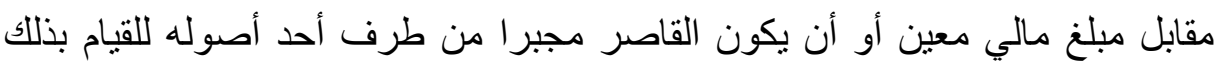

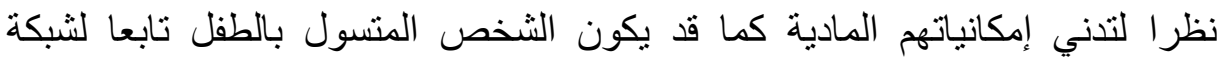
إجر امية منظمة تنشط في مجال الاتجار بالأطفال من أجل استغلالهم في التسول مقابل

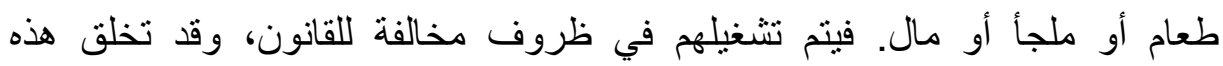

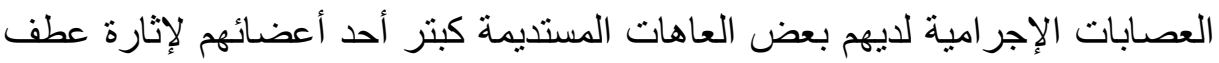

$$
\text { الناس وتكوين ثروة ضخمة باستظهار هذه العاهة. }
$$

نص المشرع الجزائري على مضاعفة العقاب المنصوص ولئه بليه في المادة 195 مكرر أعلاه، إذا كان الشخص المتسول بالقاصر هو أحد أصوله أو أي شخص له له سلطة

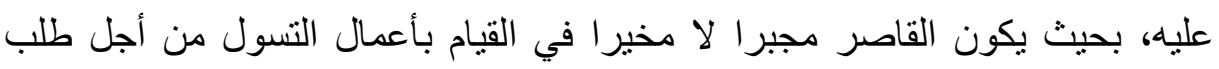

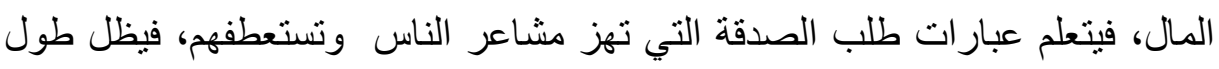
النهار واققا أو جالسا أو متنقلا قصد جمع المال، ويظهر بمظهر متسول كارتدائه

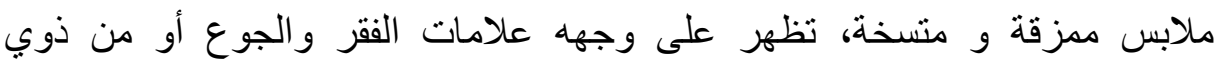

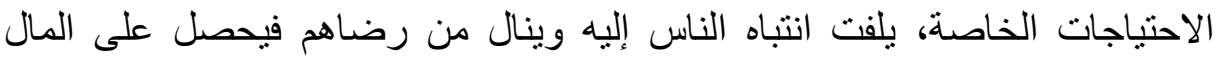
منهم. ويستوي في ذلك أن يكون الطفل القاصر ذكرا أو أنتى، مختارا أو مرغما ومجبرا

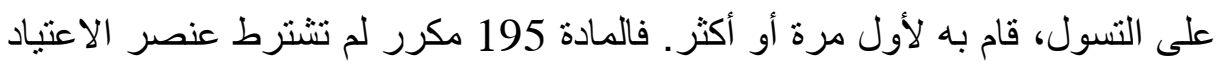

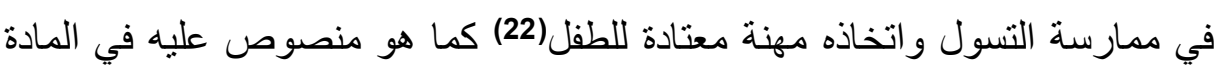
195 من نفس القانون.

كما يقوم الركن المادي لهذه الجريمة إذا عرض القاصر للتسول بأي شكل من

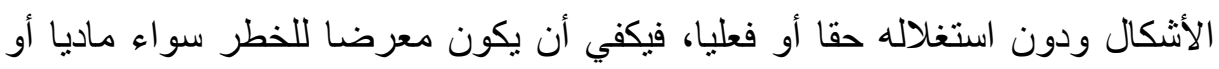
معنويا أو بمعنى أخر في سلامنه البدنية أو النفسية أو الأخلاقية. 
من هذا المنطلق تعد جريمة التسول باستعمال قاصر من الجرائم الثكلية التي لا

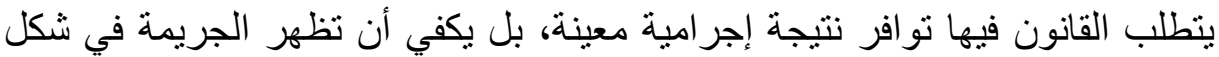

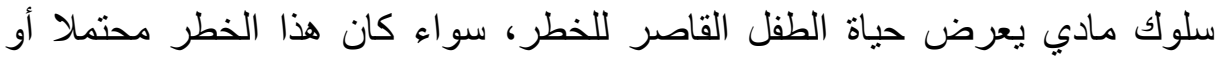

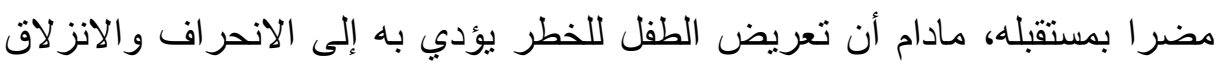

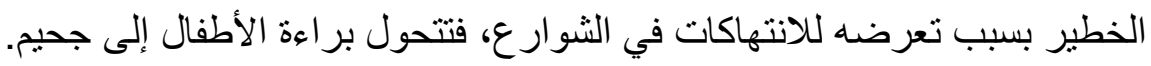

وتكمن علة المشرع الجزائري في تجريم التسول بقاصر أو تعريضه للتسول سواء

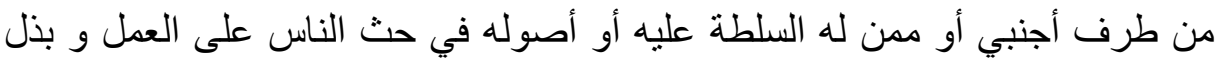

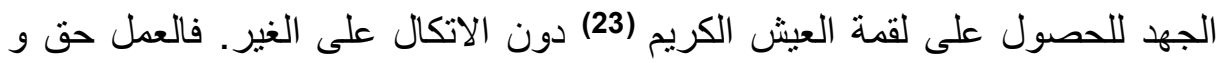
واجب على كل من يتمتع بكامل قواه العقلية و الجسدية. فحماية القاصر من الآثار

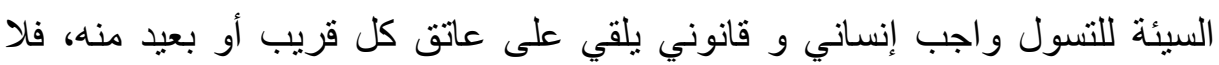

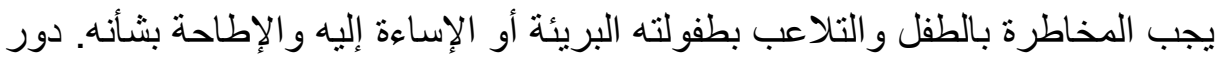

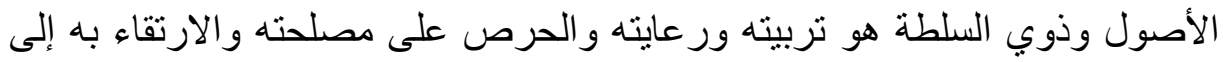

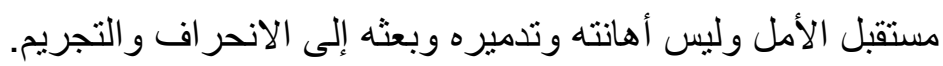

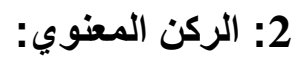

لا يكفي لقيام أي جريمة ارتكاب عمل مادي ينص ويعاقب عليه قانون العقوبات و إنما يجب أن تكون لماديات الجريمة التي يتكون منها هذا الركن انعكاس في نفي فئية

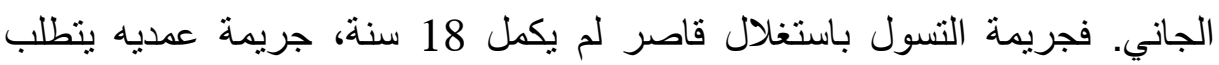
القانون نوفر فيها الركن المعنوي إلى جانب الركن المادي، أي القصد الجنائي القائم

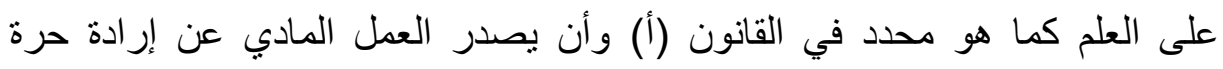

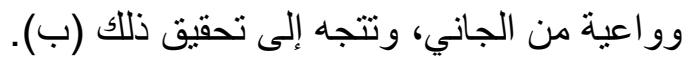
أ: العلم : اعلة :

القاعدة أنه لكي يتوفر العلم الذي يقوم به القصد الجنائي إلى جانب الإرادة، يجب

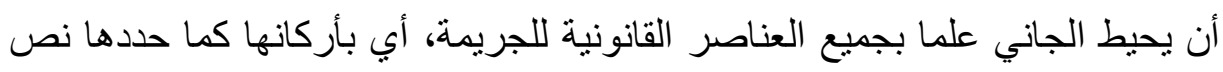

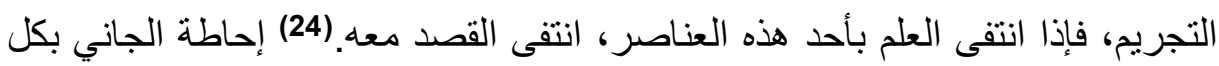

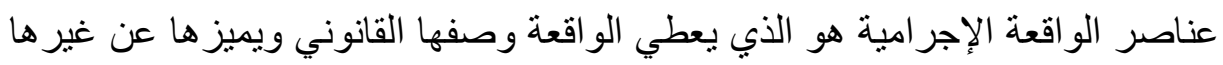

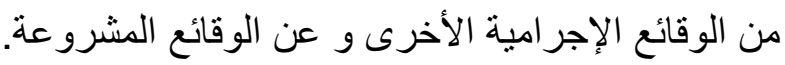

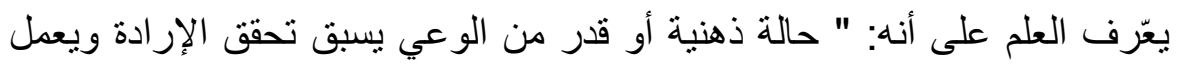

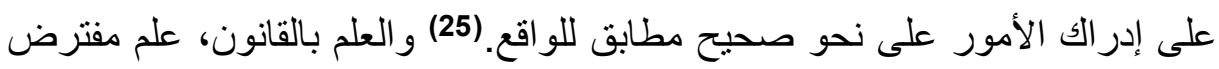

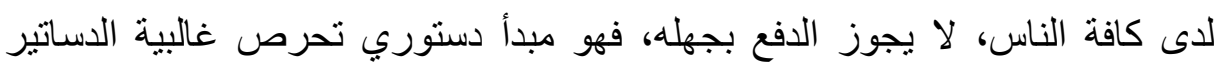
على احتر ام تطبيقه. الأصل أن الثخص في جريمة التسول باستعمال قاصر، يكون عالما بماديات

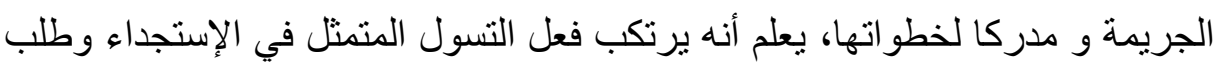

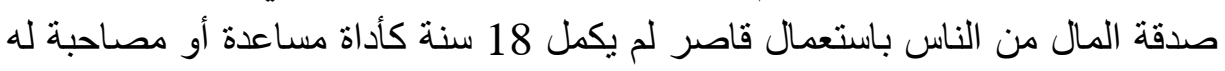
أو أنه يعرض حياته لخطر سواء كان ماديا أو معنويا و سواء كان ذلك طو اعية أو لو 
جبرا، و بالتالي فهو يعتدي على حق محمي قانونا و هو حياة طفل برئ، مع العلم بخطورة الفعل الذي يقوم به.

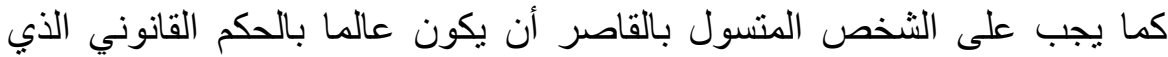

ينظم هذه الجريمة لأن العلم بالقانون مفترض مسبقا.

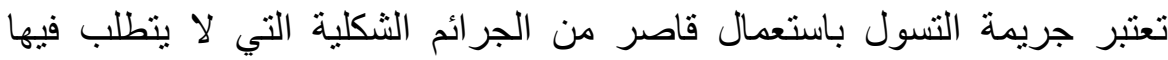

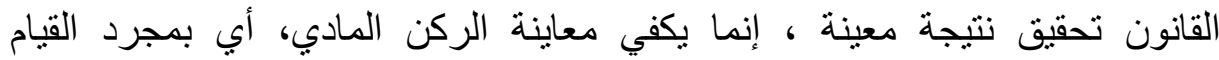

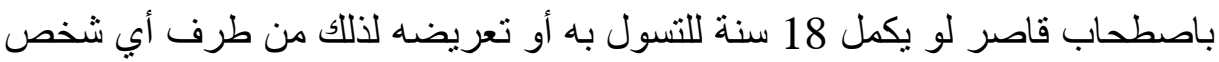
أجنبي، أو من أحد أصوله، أو ممن له السلطة عليه، تقوم الجريمة قانونا لأن نص المادة 195 مكرر السابقة الذكر لا تثترط أن يكون الثخص الثنه الهنهول قد تسلم العطاء فعلا، بل يتوفر القصد الجنائي بمجرد طلب العطاء والإحسان.

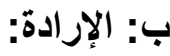

تعتبر الإر ادة العنصر الثاني للقصد الجنائي. وهي عبارة عن قوة نفسية أو نشاط

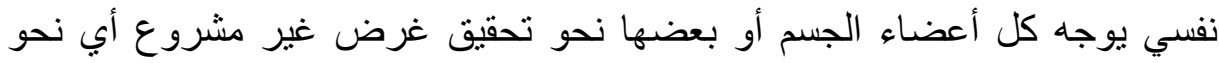

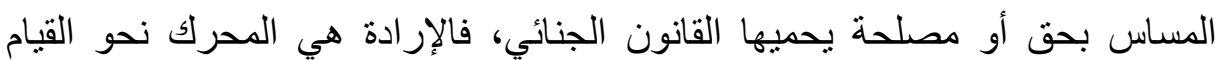

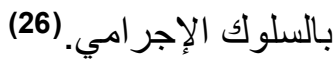
لا يكفي لقيام جريمة التسول باستغلال قاصر توفر العلم بوقائع الجريمة

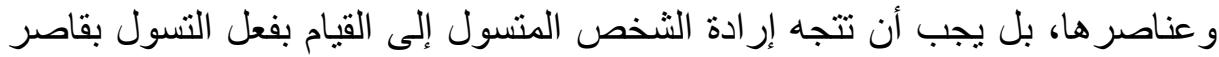

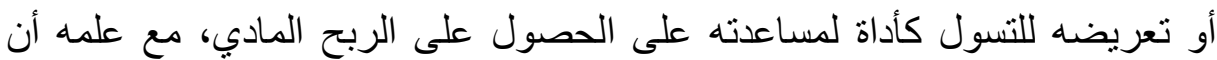

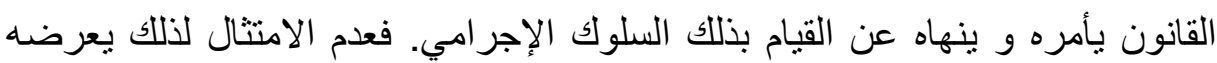

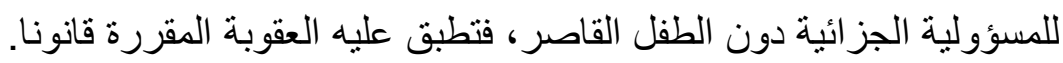
انطلاقا مما سبق، فإن توفر الإرادة الحرة و الواعية للقيام بارتكاب إحدى عناصر

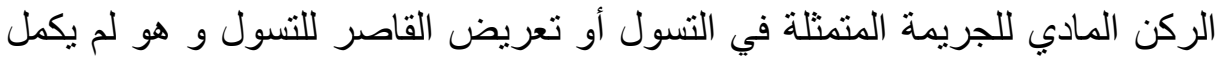

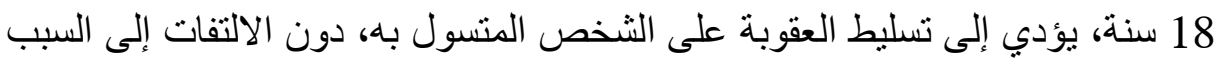

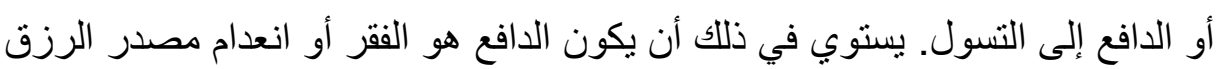

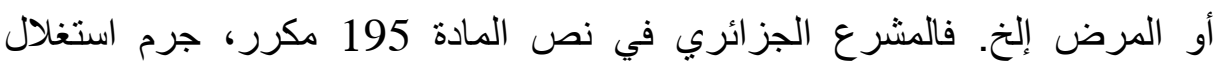
الأطفال القصر في التسول أو تعريضهم للتسول بشكل مطلق، دون النظر إلى ما إذا كان الثخص المرتكب لجريمة التسول بقاصر يملك وسيلة العيش أو باستطاعته

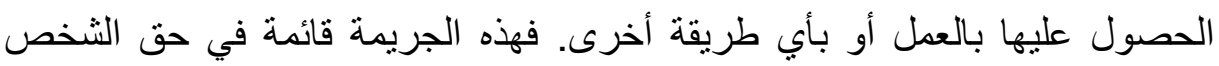
المتسول سواء كان أجنبيا أو أحد أصول القاصر أو من طرف شخص له السلطة عليه،

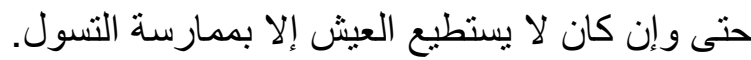
ثانيا: جزاء جريمة استغلال قاصر في التسول: نصت المادة 195 مكرر السابقة الذكر بصفة مطلقة على الأشخاص الذين يسألون جزائيا على جريمة التسول بقاصر. ويدخل تحت هذه الصفة أي شخص يرتكب

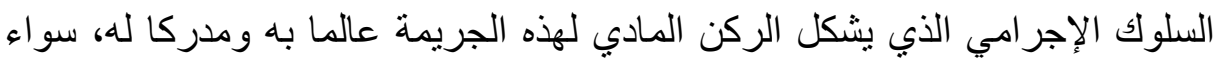
كان هذا الثخص أجنبيا عن القاصر لا صلة له به، كأن يكون من العصابات الإجرامية المنظمة والمنشطة في مجال المتاجرة بالأطفال واستغلالهم في التسول أو لأون 
تعريضهم لذلك. كذلك الأصول، كالأب والأم والجدة والجد، وكل شخص له سلطة على القاصر بدرجة قرابة أو دونها.

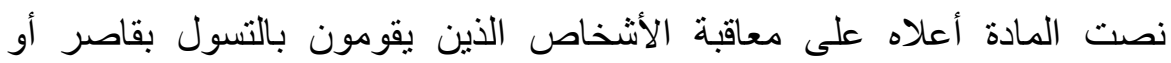

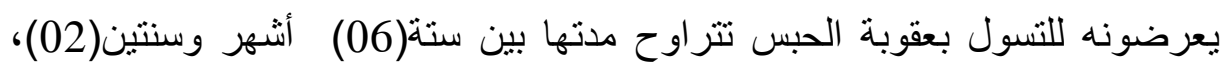

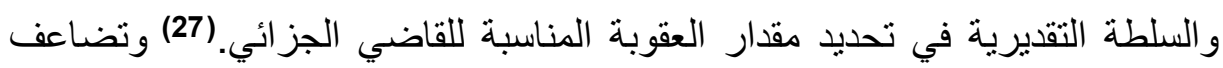

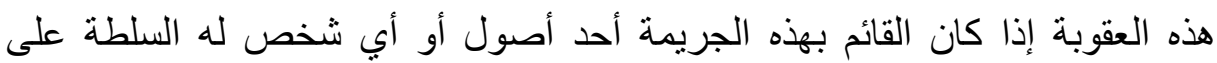
القاصر . (28)

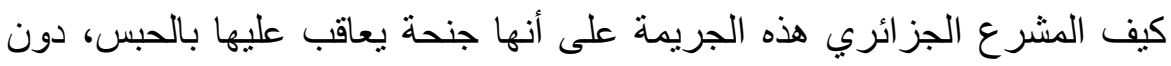

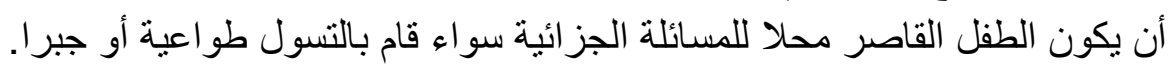

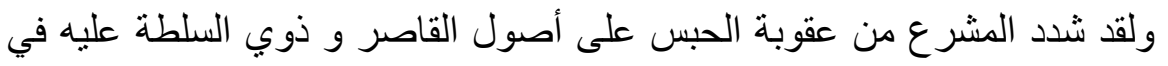

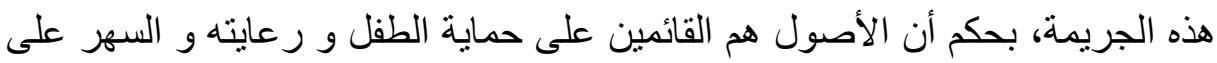
عدم تعريضه للخطر مهما كان نوعه. ويشكل هذا الدور واجبا قانونيا يلقي على عائى عاتقهم ويحاسبون عليه ويسري نفس الحكم على الثخص الذي يمارس السلطة على على القاصر.

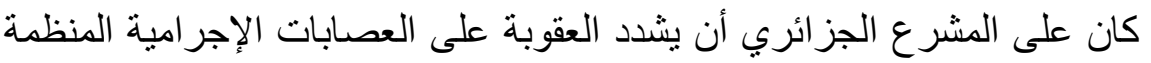

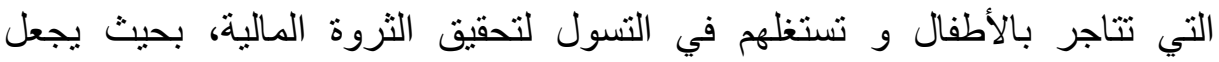
جريمتهم تأخذ وصف الجناية ويقرر لها العقوبة المناسبة، لأن القاصر قد يكون ضئن ضحية جر ائم أخرى من طرف هذه العصابات. ولقد أحسن المشرع الجزائري عندما لم يشترط في نص المادة 195 مكرر

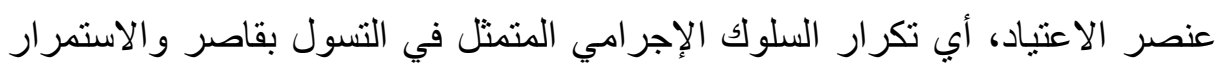
فيه، لأن التسول به ولو لمرة واحدة يعرض حياته لخطر محتمل أو محقق مستقبلا

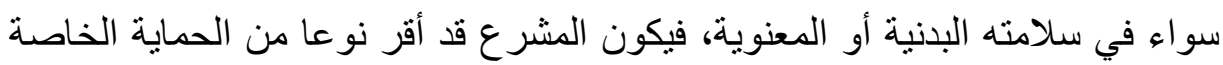
للقاصر في هذه الجريمة.

\section{ـالخاتمة:}

تعتبر جريمة التسول بقاصر مشكلة اجتماعية تؤرق المجتمع و تهدد أمنه

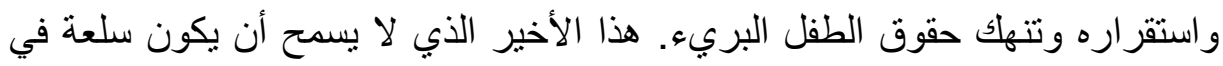

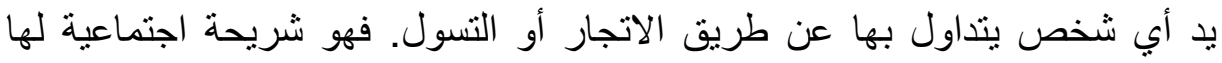

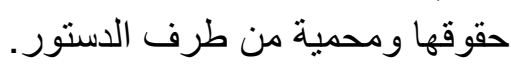

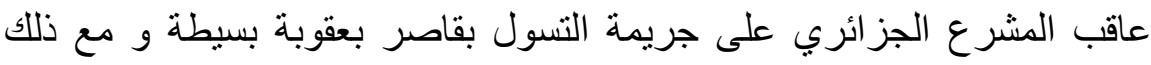

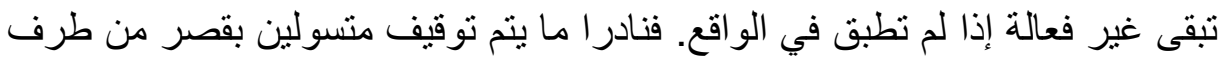

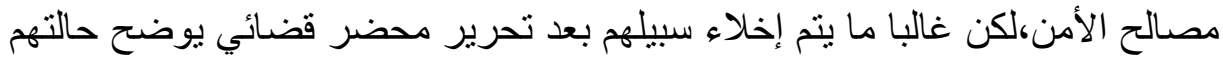

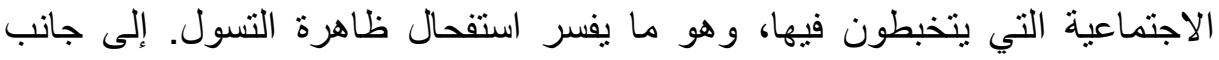

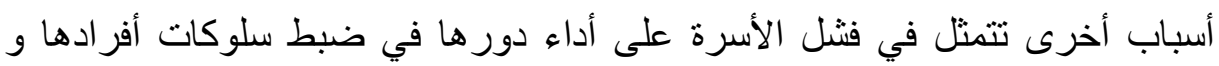
قعود أجهزة الدولة على محاربتها و الحد من تفاقمها.

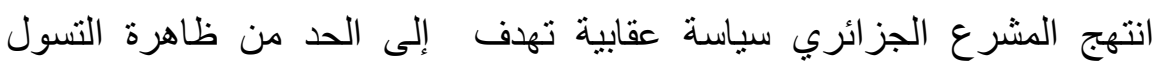


باستغلال أطفال لم يكتمل لديهم سن الثامنة عشر من عمرهم، لكن تنتابها ثغرات يرجى تداركها. - تفعيل النصوص القانونية بعد إعادة النظر فيها و تعديلها لتكون فعالة أكثر في محاربة ظاهرة التسول و عدم إستفحالها. ـ التشديد في العقاب على هذه الجريمة، و التفرقة بين التسول الذي يمارس من طرف

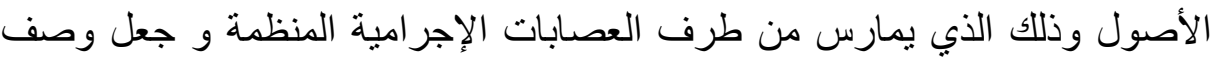

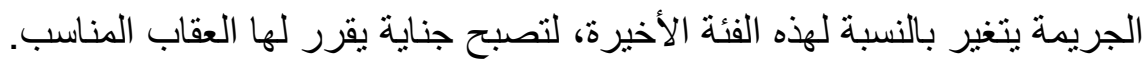
ـ تفعيل مؤسسات الدولة من أجل محاربة هذه الظاهرة الخطيرة.

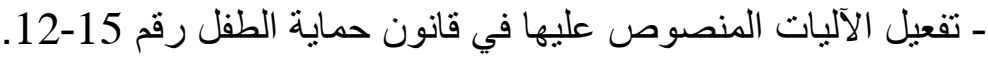
ـ تفعيل أدوات الضبط الإجتماعي، بتوعية المجتمع المدني بمخاطر التسول بقاصر للحد من إنتشاره. ـ تفعيل السياسة التربوية و التعليمية للحد من التسرب المدرسي و إنشاء مراكز

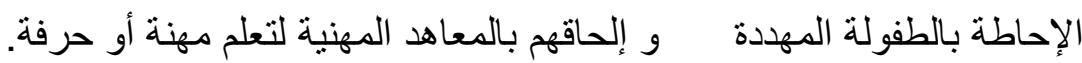
ـ التوعية الإعلامية المتكررة لمخاطر التسول بقاصر سواء المرئية أو المسموعة أو أو المدة.

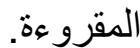

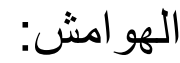
1 - قانون رقم 16-01 مؤرخ في 06 مارس 2016، يتضمن التعديل الدستوري، ج.ر.ج.ج.د.ش عن عدد

$$
\text { 14، صادر بتاريخ } 07 \text { مارس } 2016 .
$$

2 ـ قانون رقم 12-15 مؤرخ في 15 يوليو 2015، ينعلق بحماية الطفل، ج.ر.ج.ج.د.ش، عدد 39 ، صادر بتاريخ 19 جويلية

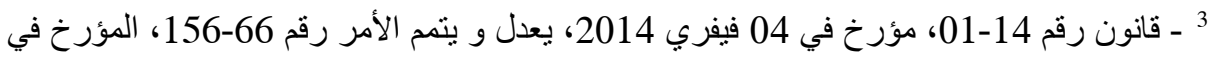

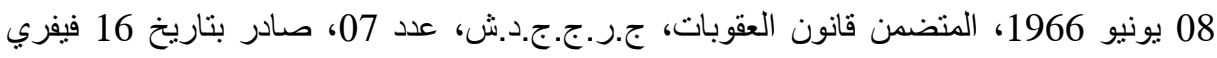

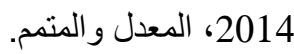
4 - رزاقي نبيلة، جريمة التسول في ظل تعديلات قانون العقوبات 2014، مجلة بحوث جامعة

$$
\text { الجزائر 1، العدد 8، } 30 \text { جوان نيله، 2015، ص } 130 .
$$

5 ـ بن عمر ياسين، عمامرة مباركة، الأطفال ضحايا الإستغلال في التسول بين النصوص القانونية و الأهداف المنشودة، المجلة الدولية للبحوث القانونية و السياسية، المجلد 2، العدد 3، ديسمبر 2018، ص

6 - مصبايح فوزية، التسول من منظور القانون الوضعي و الثريعة الإسلامية، مجلة الحكمة

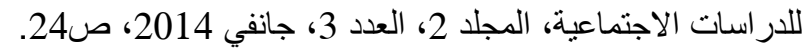
7 ـ نهله سعد عبد العزيز، المسؤولية الجنائية للطفل، دار الفكر و القانون، المنصورة، 2014، 2017، 
9 ـ عبد العزيز بن إبراهيم بن ناصر الفايز، الأبعاد الأمنية لظاهرة التسول في المجتمع السعودي،

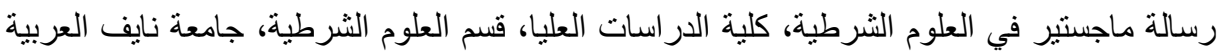

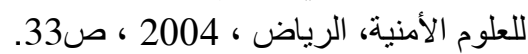

$$
10 \text { ـ مصبايح فوزية، مرجع سابق، ص26 الأنية ، }
$$

11ــ إيناس محمد البهجي ، جرائم الإتجار بالبشر، المركز القومي للإصدارات القانونية، القاهرة،

$$
\text { 2013، ص55 }
$$

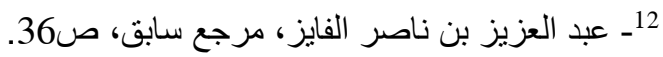

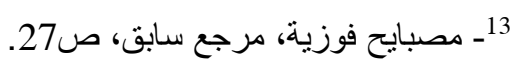

14

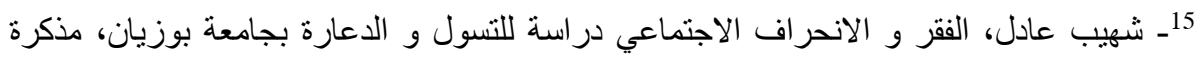

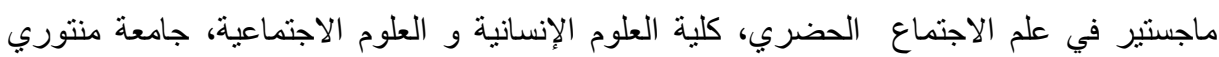

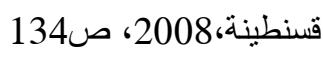

16ـ عبد الله بن مشبب بن عبادي القحطاني، السياسة الجنائية لككافحة التسول، رسالة ماجستير في العدالة الجنائية، معهد الدراسات العلبا، قسم العدالة الاجتماعية، جامعة نايف العربية للعلوم الأمنية،

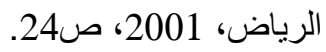
17 ــ وهو ما نصت عليه المادة الأولى من قانون العقوبات:"لا جريمة و لا عقوبة أو تدابير أمن بغير قانون" 18 ـ الإتفاقية الدولية لحقوق الطفل، إعتمدت بموجب قرار الجمعية العامة للأمم المتحدة رقم 25/44

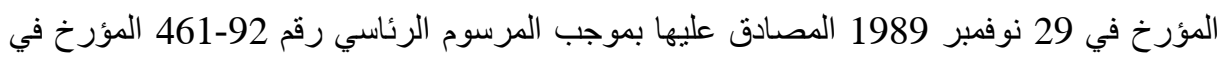

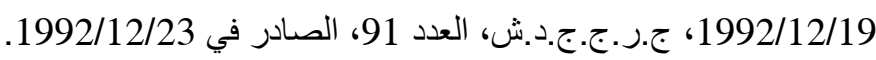

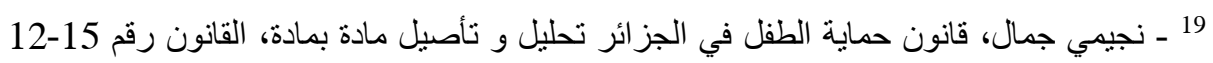

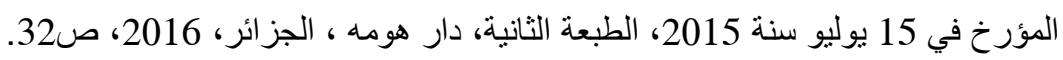

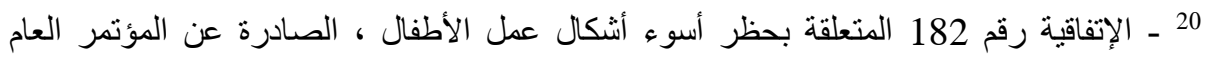

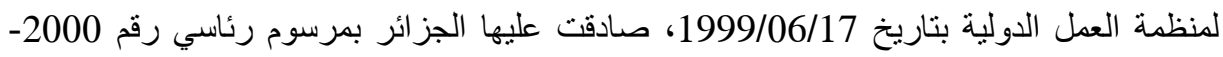
387 المؤرخ في 2000/11/28، ج.ر.ج.ج.د.ش، العدد 73، الصادر في 2000/12/03.

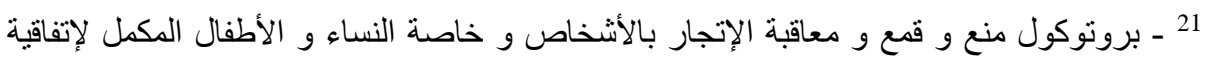

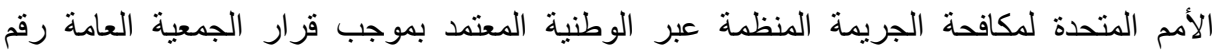

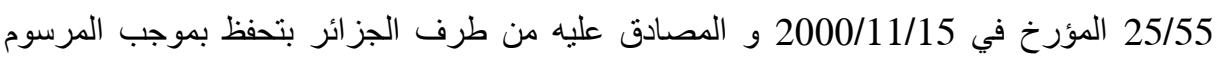

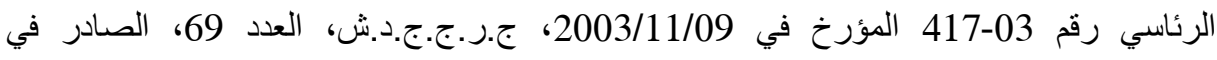

.2003/11/12

ـ شرط الإعتباد منصوص عليه في المادة 195 من القانون رقم 14-01/12 السابق ذكره 22 ـ 203

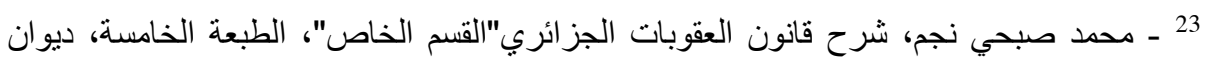

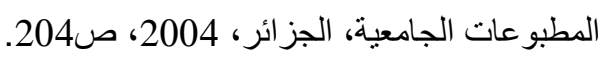

24 ـ علي عبد القادر القهوجي، قانون العقوبات، القسم العام، دار الجامعية، 1994، ص ص204، 218.

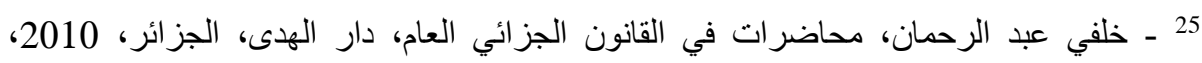


26 ـ عبد القادر القهوجي، مرجع سابق، ص227. 27 ـ أنظر، الفقرة الأولى من المادة 195 مكرر السابقة الذكر.

28 ـ أنظر، الفقرة الثانية من المادة 195 مكرر السابقة الذكر. لـمراجـع

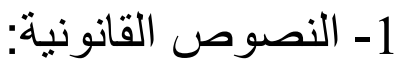

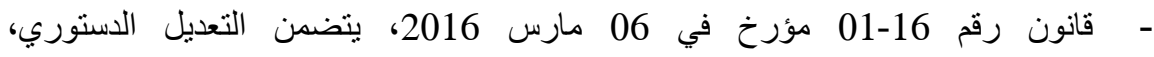

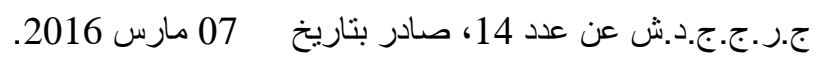

- الإتفاقية الدولية لحقوق الطفل، إعتمدت بموجب قرار الجمار الجمعية العامة للأمم المتحدة رقم

25/44 المؤرخ في 29 نوفمبر 1989 المصادق عليها بموجب المرسوم الرئاسي رقم

461-92 المؤرخ في 1992/12/19، ج.ر.ج.ج.د.ش، العدد 91، الصادر في

$.1992 / 12 / 23$

- الإتفاقية رقم 182 المتعلقة بحظر أسوء أنشكال عمل الأطفال ، الصادرة عن المؤتمر العام

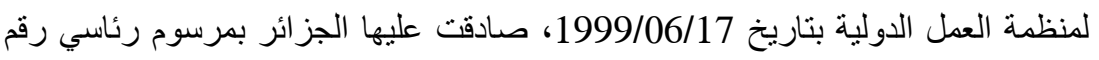

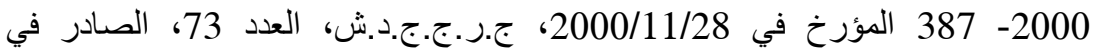

2000/12/03

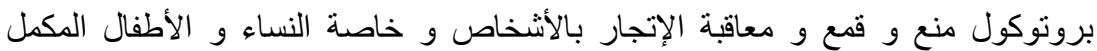

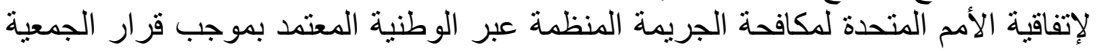

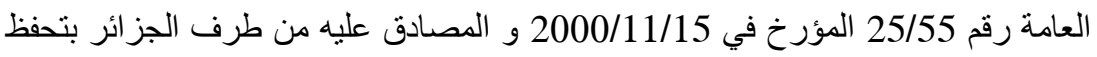

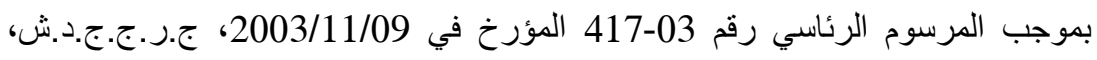
العدد 69، الصادر في 2003/11/12.

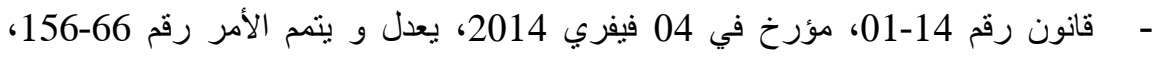

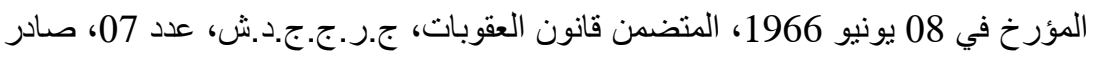
بتاريخ 16 فيفري 2014، المعدل و والمتمئم قانون رقم 12-12 مؤرخ في 15 يوليو 2015، ينعلق بحماية الطفل، ج.ر.ج.ج.د.ش، عدد

39 ، صادر بتاريخ 19 جويلية 2015.

- نهله سعد عبد العزيز، المسؤولية الجنائية للطفل، دار الفكر و القانون، المنصورة، 2017.

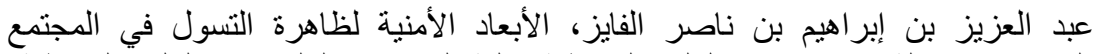
السعودي، رسالة ماجستير في العلوم الثرطية، كلية الدراسات العائية العليا، قسم العلوم الثرطية، جامعة نايف العربية للعلوم الأمنية، الرياض ، 2004. إيناس محمد البهجي ، جرائم الإتجار بالبشر، المركز القومي للإصدارات القانونية، القاهرة،

- جيمي جمال، قانون حماية الطفل في الجزائر تحليل و تأصيل مادة بمادة، القانون رقم 15-

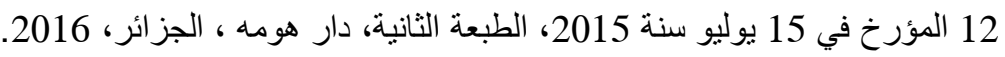

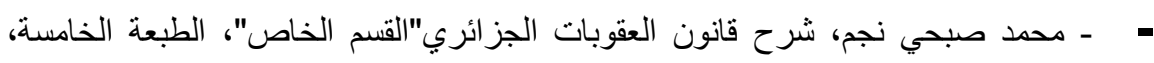
ديوان المطبو عات الجامعية، الجز ائر، 2004. 
- خلفي عبد الرحمان، محاضرات في القانون الجزائي العام، دار الهدى، الجزائر، 2010.

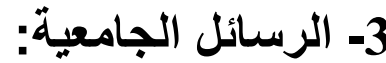

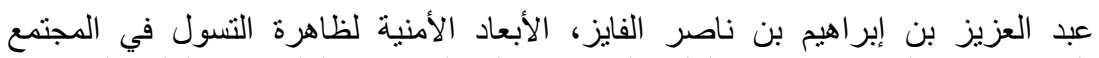
السعودي، رسالة ماجستير في العلوم الثرطية، كلية الدراسات العليا، قسم العلوم الثرطية، الثرائ. جامعة نايف العربية للعلوم الأمنية، الرياض فلئر ، 2004.

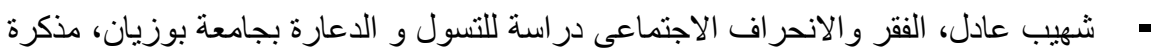

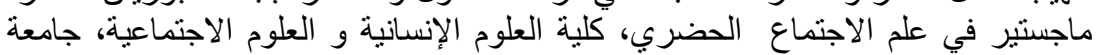

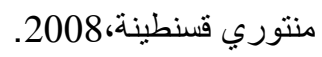

- عبد الله بن مشبب بن عبادي القحطاني، السياسة الجنائية لمكافحة التسول، رسالة ماجستير

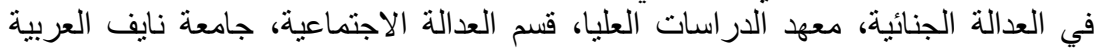

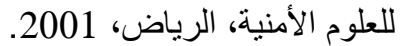
4- المقالات العلمية: - رزاقي نبيلة، جريمة التسول في ظل تعديلات قانون العقوبات 2014، مجلة بحوث جامعة

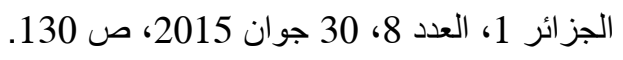

- -

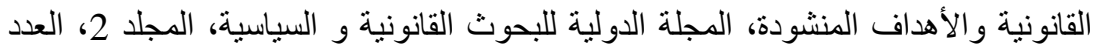

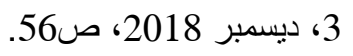

- - مصبايح فوزية، التسول من منظور القانون الوضعي و الثريعة الإسلامية، مجلة الحكمة لللار اسات الاجتماعية، المجلد 2، العدد 3، جانفي 2014، صنابعة ص24. 